\title{
A Certain Naval Gun on Empty Firing Command Decision Research Changpeng $\operatorname{Pan}^{1, a}$ and Liang $\mathrm{Ma}^{2, \mathrm{~b}}$ \\ ${ }^{1}$ Naval Aeronautical and Astronautical University, Yantai, 264001, China; ${ }^{2}$ Department of Surface Ship Command, Dalian Naval Academy, Dalian, 116018, China a285892287@qq.com, bmaliang2014@tom.com
}

\section{Keywords: Naval gun firing command; Decision making in the air}

\begin{abstract}
The operational effectiveness of naval gun's anti-air besides related to naval gun weapon system, also to a large extent under the influence of firing command decision making. How to reasonable use of naval gun weapon system's anti-air, we need to empty for naval gun firing command decision making problems for further research. In this paper, a new type of empty naval gun firing command decision making analysis of elements, puts forward the requirements and methods of empty firing command decision making, to combat troops actually use the new naval gun and training to provide guidance and reference.
\end{abstract}

\section{The Air Shot Firing Distance}

Fire Maximum Effective Distance on Air Targets. Will target into effective field of fire edge points as early point, the corresponding target now known as the maximum effective distance oblique fire distance. The firing distance refers to the first some starting moment of target distance. Maximum firing distance calculated by the next type:

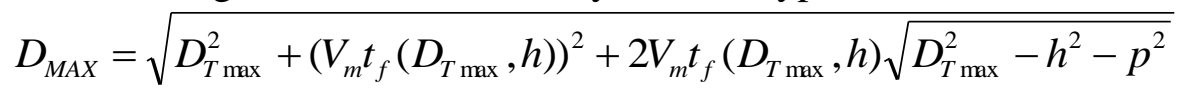

Type: $D_{T \max } \longrightarrow$ a certain naval gun for aircraft use the range of a proximity fuze killer explosive grenade, take $6000 \mathrm{~m} . V_{m} \longrightarrow$ target speed; $h$ — target height; $p$ — route tick size; $t_{f}$ the projectile flying time.

To target different shooting conditions maximum firing distance calculation result list 1 .

Table 1 A certain naval gun killing of proximity fuze explosive grenade maximum firing distance table to the aircraft

\begin{tabular}{|c|c|c|c|c|c|c|c|}
\hline \multirow{2}{*}{$P$} & \multirow{2}{*}{$V_{m}$} & \multicolumn{7}{|c|}{$H$} \\
\cline { 2 - 7 } & 200 & 100 & 500 & 1000 & 1500 & 2000 & 2500 \\
\hline \multirow{3}{*}{0} & 250 & 8525 & 8519 & 8500 & 8468 & 8423 & 8362 \\
\cline { 2 - 8 } & 300 & 9030 & 9023 & 9002 & 8966 & 8914 & 8845 \\
\hline \multirow{3}{*}{1000} & 200 & 7999 & 7994 & 7977 & 7950 & 7910 & 7858 \\
\cline { 2 - 8 } & 250 & 8450 & 8494 & 8475 & 8443 & 8396 & 8334 \\
\cline { 2 - 8 } & 300 & 9002 & 8995 & 8973 & 8937 & 8884 & 8813 \\
\hline \multirow{3}{*}{2000} & 200 & 7933 & 7928 & 7910 & 7881 & 7840 & 7783 \\
\cline { 2 - 8 } & 250 & 8423 & 8416 & 8396 & 8362 & 8313 & 8246 \\
\cline { 2 - 8 } & 300 & 8914 & 8907 & 8884 & 8845 & 8789 & 8714 \\
\hline
\end{tabular}

From Table 1 shows that maximum firing distance is mainly related to the target speed, and affected by the target height, tick size is very small. For ease of use and grasp, to the above-mentioned attribute processing, maximum firing distance $(\mathrm{m})$ of simplified calculation formula is: $D_{\max }=8000+10 \times\left(V_{m}-200\right)$

Words can be expressed as: when the target speed $200 \mathrm{~m} / \mathrm{s}$, maximum firing distance take 8000 $\mathrm{m}$; Each target speed increase (or decrease) of $50 \mathrm{~m} / \mathrm{s}$, maximum firing distance increase (or decrease) $500 \mathrm{~m}$. 
Symbols and Meaning with The Previous Type.

When the parachute low-speed flying helicopters, target shooting, flare when, if the approximate think its velocity is zero, according to the type of fire can calculate the maximum distance of 6000 meters. Due to such target relative to the other air target threat degree is low, the use of prefabricated fragment of proximity fuze bullet for larger volume of helicopter shooting, even long distance shooting has certain effectiveness. Proximity fuze killer blasting grenade fuze since the frying time XX (s), corresponding projectile flying distance of about $10000 \mathrm{~m}$. Under special circumstances, to within $10000 \mathrm{~m}$ of parachute helicopters, target class can be shot.

When Using Photoelectric Equipment Found Sea-Skimming Missiles Fired Immediately. This is because the anti-ship missile is currently the main weapon of the attacking ships, has small volume, high speed and precision, the characteristics of great power. For sea-skimming missile flight, flight altitude is lower and are less likely to be found, and the fight against more difficult. Ships once been hit will cause serious damage, even sinking. So should fully consider the actual combat ships equipment such goal of practical ability, to maximize the firepower and counter missiles, with the quickest speed to ensure the safety of the ship.

Existing photoelectric equipment performance show that the visibility is good, the use of photoelectric channel of sigma $=0.1 \mathrm{~m}^{2}$ sea-skimming missile target, when the target speed is $1 \mathrm{ma}$, maximum tracking distance (including laser ranging) at about $7500 \mathrm{~m}$. At present, most of the anti-ship missile terminal guidance period at a rate of $0.8 \mathrm{Ma} \sim 0.9 \mathrm{Ma}$, considering the influence of various kinds of actual combat condition, photoelectric channel to the sea or rapid small target effective observation distance within $7500 \mathrm{~m}$. A certain naval gun weapon system to response time for X seconds, assuming that the rate of $300 \mathrm{~m} / \mathrm{s}$ sea-skimming flight of the missile attack to me, is this system for maximum firing distance of target has been in my largest naval gun weapon system within the field of fire effectively, maximum firing duration is only about 17 s. So when using photoelectric equipment found sea-skimming missiles should be fired immediately.

\section{The Means of Transmission and Shooting Method}

The Air Shot Selection. For all kinds of air target, because of the large target threat shooting duration is short, must organize the largest fire fighting, so choose the biggest rate of artillery launch.

To Track on the Fire Shooting Method. Tracking shooting is refers to the artillery systems continuous tracking target, calculate target point coordinate in advance ceaselessly, make shooting the yuan in advance of moving targets with points corresponding to a way of shooting. Effective air targets in the naval gun range, in order to ensure the effect does not generally make large motor, such as sea-skimming anti-ship missiles have already entered the stage of terminal guidance, usually USES the proportional guidance law to ship; The plane has already entered the attack route. A naval gun weapon system to deal with such a goal has enough accuracy, at the same time the system is also does not have the required by the barrage firing power density, so the system tracking firing modes to shoot, the effect will be the best.

Some Length and Some Intervals. Naval gun weapon system firing mode is divided into three types: short, some long some, even a shot. Some directly on the launch of a certain length (single pipe with theory of emissivity of a continuous firing shells), some interval (the time interval between some and some) for the shoot, some long, short some firing interval length and some different, some usually in continuous some methods, which to some length, some several times launched some time interval. Shoots and is the largest naval gun firing rate continuously launch a period of time, until the emission limits or has been ordered to stop shooting.

A certain naval gun weapon system for different target calculation results see list 2 different shooting conditions. 
Table 2 Different Shooting Conditions To XX Target Shooting Effect

\begin{tabular}{|c|c|c|c|c|}
\hline \multirow{2}{*}{$\begin{array}{l}\text { Isolation } \\
\text { between point } \\
\text { shot }\end{array}$} & \multirow{2}{*}{$\mathrm{N} \quad \mathrm{Vm}$} & \multicolumn{3}{|c|}{$\mathrm{H}=5$} \\
\hline & & 300 & 350 & 400 \\
\hline \multirow{5}{*}{1.0} & 2 & 0.195 & 0.175 & 0.170 \\
\hline & 4 & 0.230 & 0.204 & 0.190 \\
\hline & 6 & 0.238 & 0.223 & 0.200 \\
\hline & 8 & 0.245 & 0.216 & 0.209 \\
\hline & 10 & 0.257 & 0220 & 0.213 \\
\hline \multirow{5}{*}{1.5} & 2 & 0.163 & 0.145 & 0.140 \\
\hline & 4 & 0.202 & 0.188 & 0.175 \\
\hline & 6 & 0.228 & 0.203 & 0.190 \\
\hline & 8 & 0.239 & 0.217 & 0.202 \\
\hline & 10 & 0.245 & 0.211 & 0.201 \\
\hline \multirow{5}{*}{2.0} & 2 & 0.149 & 0.124 & 0.120 \\
\hline & 4 & 0.192 & 0.177 & 0.157 \\
\hline & 6 & 0.217 & 0196 & 0.183 \\
\hline & 8 & 0.234 & 0.202 & 0.188 \\
\hline & 10 & 0.235 & 0.216 & 0.194 \\
\hline \multirow{5}{*}{2.5} & 2 & 0.129 & 0.120 & 0.110 \\
\hline & 4 & 0.176 & 0.164 & 0.155 \\
\hline & 6 & 0.198 & 0.190 & 0.178 \\
\hline & 8 & 0.226 & 0.203 & 0.182 \\
\hline & 10 & 0.230 & 0.213 & 0.191 \\
\hline \multirow{5}{*}{3.0} & 2 & 0.121 & 0107 & 0.102 \\
\hline & 4 & 0.181 & 0.164 & 0.143 \\
\hline & 6 & 0.200 & 0.190 & 0.171 \\
\hline & 8 & 0.207 & 0.204 & 0.179 \\
\hline & 10 & 0.215 & 0208 & 0.194 \\
\hline
\end{tabular}

Through the analysis of Table 2 and combined with the principle of empty fire control knowledge, the system optimal point shoot length of $4 \sim 8$, some interval time interval is $1 \sim 3 \mathrm{~s}$, the damage probability and damage probability with increasing the ratio of the larger. So the naval gun weapon system take the most advantage at the lower limit of the length of the short some length, length of long some take the most advantages of shoot length limit, some take $1 \sim 3 \mathrm{~s}$ interval.

\section{A Shooting Mode of Shooting in the Air}

Fixed Wing Aircraft to Fly Way of Shooting. (1) when the target distance is greater than 6000 meters, with short some way

When the target when firing distance into the biggest, we have to consider from the target into the 8000 meters started shooting, for in a normal way to attack aircraft, which can shoot time about $25 \sim 50$ seconds. If the whole shooting range using shoots, likely beyond the limit of continuous shooting fired several; But if by some way, can guarantee not beyond the limit of continuous shooting fired several. Given at the same time, when the target into maximum firing distance but in the 6000 metres away, because the distance is far, the shooting effect is poorer, can be shooting with a short some.

(2) some long distance $D_{L}$

Goals, after close to shooting effect gradually turned for the better, you should use some long. In order to determine a suitable long, some began to distance of each point distance ahead of long some route list of firing effectiveness in all three. 
Table 3 A certain naval gun's long distance from some early damage probability interval (2 s)

\begin{tabular}{|c|c|c|c|c|c|c|c|c|}
\hline \multirow{2}{*}{ V } & \multirow{2}{*}{$\mathrm{H}$} & \multicolumn{5}{|c|}{ Distance D in advance } & \multicolumn{2}{|l|}{ Now target distance (m) } \\
\hline & & 3000 & 3500 & 4000 & 4500 & 5000 & Normal calculated value & Merge the value \\
\hline \multirow{3}{*}{200} & 100 & 0.592 & 0.600 & 0.606 & 0.611 & 0.616 & 5137.7 & \multirow{3}{*}{5100} \\
\hline & 500 & 0.823 & 0.836 & 0.837 & 0.841 & 0.844 & 5140.9 & \\
\hline & 1000 & 0.922 & 0.926 & 0.929 & 0.931 & 0.933 & 5080.3 & \\
\hline \multirow{3}{*}{250} & 100 & 0.537 & 0.549 & 0.558 & 0.563 & 0.567 & 5422.2 & \multirow{3}{*}{5400} \\
\hline & 500 & 0.781 & 0.787 & 0.792 & 0.796 & 0.798 & 5426.7 & \\
\hline & 1000 & 0.866 & 0.870 & 0.873 & 0.875 & 0.876 & 5352.3 & \\
\hline \multirow{3}{*}{300} & 100 & 0.493 & 0.508 & 0.517 & 0.522 & 0.524 & 5706.6 & \multirow{3}{*}{5700} \\
\hline & 500 & 0.735 & 0.741 & 0.745 & 0.748 & 0.751 & 5712.5 & \\
\hline & 1000 & 0.810 & 0.813 & 0.815 & 0.817 & 0.818 & 5624.6 & \\
\hline
\end{tabular}

Data from Table 3 shows that when the point distance is greater than 4000 meters ahead, a long some kill probability increased modestly. As a result, some long distance 4000 meters ahead of time. When the target hook JingQu zero, the corresponding distance as shown in table 3 right now. By table 4 shows that long now some target distance $D_{L}$ is mainly related to the target speed, less influence by the target height. For ease of use and grasp, to the above-mentioned attribute processing, draw a long some target distance $D_{L}(\mathrm{~m})$ now simplified calculation formula is:

$$
D_{L}=5100+6 \times\left(V_{m}-200\right)
$$

Words can be expressed as: when the target speed $200 \mathrm{~m} / \mathrm{s}$, some target distance now take 5100 $\mathrm{m}$ long; Each target speed increase (or decrease) of $50 \mathrm{~m} / \mathrm{s}$, long some target distance increase (or decrease) $300 \mathrm{~m}$ now.

(3) even began to distance $D_{c}$

The closer the target distance, shooting effect is better, so the target on the distance of the shooting dead zones should carry on the biggest fire fighting of naval gun. In order to determine the appropriate even shoot length, different situation of shooting results listed in Table 4:

Table4 A certain naval gun for aircraft even shoot length range effect $(\mathrm{P}=0)$

\begin{tabular}{|c|c|c|c|c|c|c|c|c|c|}
\hline \multirow{2}{*}{$\mathrm{N}$} & \multicolumn{3}{|c|}{$\mathrm{Vm}=50$} & \multicolumn{3}{c|}{$\mathrm{H}=100$} & \multicolumn{3}{c|}{$\mathrm{H}=500$} \\
\cline { 2 - 10 } & 200 & 250 & 300 & 200 & 250 & 300 & 200 & 250 & 300 \\
\hline 2 & 0.337 & 0.317 & 0.304 & 0.370 & 0.353 & 0.337 & 0.554 & 0.547 & 0.530 \\
\hline 4 & 0.420 & 0.399 & 0.378 & 0.461 & 0.433 & 0.418 & 0.682 & 0.665 & 0.646 \\
\hline 6 & 0.476 & 0.445 & 0.428 & 0.515 & 0.498 & 0.469 & 0.756 & 0.724 & 0.692 \\
\hline 8 & 0.500 & 0.457 & 0.456 & 0.555 & 0.532 & 0.499 & 0.791 & 0.763 & 0.729 \\
\hline 10 & 0.514 & 0.464 & 0.475 & 0.591 & 0.551 & 0.525 & 0.815 & 0.780 & 0.752 \\
\hline 12 & 0.522 & 0.470 & 0.485 & 0.603 & 0.564 & 0.536 & 0.830 & 0.788 & 0.765 \\
\hline 14 & 0.528 & 0.474 & 0.493 & 0.610 & 0.572 & 0.547 & 0.842 & 0.793 & 0.773 \\
\hline
\end{tabular}

According to the gun to shoot even in aircraft under the condition of different air route, visible when the length is more than 10 12 even shoot, shoot effect increased, for convenience, will even shoot length as 10 12. In this way, the gun dartle points ahead of slant distance and now distance are shown in Table 5

Table 5 A certain naval gun dartle point now slant distance and distance in advance

\begin{tabular}{|c|c|c|c|c|c|c|c|c|c|}
\hline \multirow{2}{*}{$\mathrm{V}$} & \multirow{2}{*}{$\mathrm{P}$} & \multicolumn{9}{|c|}{$\mathrm{H}$} & \multicolumn{2}{c|}{1000} \\
\cline { 3 - 10 } & & 50 & 100 & 500 & 1813 & 1510 & 1785 \\
\hline \multirow{2}{*}{200} & 0 & 1572 & 1933 & 1570 & 1930 & 1478 & 1878 & 1668 & 1762 \\
\cline { 2 - 10 } & 500 & 1538 & 1875 & 1536 & 1872 & 1420 & 1712 & 1695 & 2108 \\
\hline \multirow{2}{*}{250} & 0 & 1735 & 2233 & 1733 & 2230 & 1648 & 2103 & 1841 & 2285 \\
\cline { 2 - 10 } & 500 & 1697 & 2167 & 1695 & 2164 & 1572 & 1986 & 1876 & 2450 \\
\hline \multirow{2}{*}{300} & 0 & 1883 & 2534 & 1880 & 2530 & 1795 & 2396 & 1737 \\
\cline { 2 - 10 } & 500 & 1841 & 2459 & 1838 & 2454 & 1737 & 2297 & 2011 & 2622 \\
\hline
\end{tabular}


From Table 6 shows: even shot now began to target distance is mainly related to the target speed, less influence by the target height. For ease of use and master, will be under control chart processing, it is concluded that even now shoot the target distance $(\mathrm{m})$ of the simplified calculation formula is:

$$
D_{c}=1900+6 \times\left(V_{m}-200\right)
$$

Words can be expressed as: when the target speed $200 \mathrm{~m} / \mathrm{s}$, shoots and target distance now take $1900 \mathrm{~m}$; Each target speed increase (or decrease) of $50 \mathrm{~m} / \mathrm{s}$, shoots and target distance increase (or decrease) $300 \mathrm{~m}$ now.

Shoot At Subduction. When determining the enemy dive or suddenly find that dive target should be used immediately even shot way to shoot, shoot to target destroyed or the end of the dive.

Dive attack is the plane dived at a certain Angle (15 to 45 ), a common method for surface warships attack. Usually, before the plane dived into a low flying close to the target, the discovery of the target as a complex maneuvers. Began to dive 1000 3000 meters high, common attack 500 1500 meters in height. This attack accuracy is higher, and because of bombs fall speed is big, so the penetrating power is big, so the threat to ships is bigger also, need to implement the density is larger, high accuracy of the fight.

Although the enemy into the various modes of subduction, but no matter what way into the subduction, the subduction process can be divided into three stages: enter the subduction period, linear subduction and exit the subduction. Generally enemy planes in subduction time is 2 5 seconds, straight dive segment is $6 \sim 10$ seconds, the whole duration of subduction is only $8 \sim 15$ seconds, effective naval gun firing duration is very short. In this period of time, even if has been with the method of naval gun even shoot will not reach the limit of naval gun fired several restrictions. So when determining the enemy dive or suddenly find that dive target shooting should be used immediately shoots way.

Even Shooting Mode to The Missile. Anti-ship missile has small volume, high speed, low altitude, shooting and damage characteristics of great power. Therefore, the missile's found that nearly, shooting for short, must organize the largest fire fighting.

Due to the firing duration of anti-ship missile is usually within the $30 \mathrm{~s}$, even to the biggest launch speed continuous emission ability about XX shells, will not reach the limit of naval gun fired several restrictions. Comprehensive the above, the missile shooting dartle mode should be adopted.

Parachute Helicopters Target. To parachute helicopters, short some approaches such as target shooting, use $2 \sim 3$ consecutive group of some manner, in the process of shooting in the view of shooting.

Due to shoot at such a time may be longer, adopt the way may exceed the limit fired several, is also likely to be too many may be unnecessary ammunition consumption; Considering with proximity fuze preformed fragment bullet shoot at such a certain kill probability, a need not continuous firing ammunition so much, so choose short some. Limit number of sets of some and view shooting, is in order to reduce unnecessary ammunition consumption.

\section{Shooting Observation and Firing Correction}

In the process of subduction target and aerial target quickly, should be constantly observed target movement and shooting effect, without firing correction. Shooting to the target destroyed or away from or naval commander ordered the transfer fire cease fire.

Radar observations, the distance between gate set in the center of the target, the discovery of the projectile by wave echo time measuring deviation of the door. Prefabricated fragment of the proximity fuze, should use the radar measuring average trajectory and the target direction and the height deviation value.

Using photoelectric (learn) equipment and visual observation, using artillery shells of proximity fuze, when using photoelectric equipment and visual observation, observation ZhaDian deviation value cannot be used as the basis for the correction, but should pay attention to the observation shooting effect. 
Observations ZhaDian deviation should be pay attention to the order. Tick size is equal to zero when the target route, should first determine height deviation, after direction deviation. Hook size is not equal to zero when the target route, should first determine direction deviation, the determination of high and low bias.

Tick size is not equal to zero when the target route, namely lateral flight, will be measured by the direction of the deviation of a multiple attribute for the 10 milli arc. ZhaDian appeared in front of a goal, into a multiple of that of the 10; ZhaDian appeared behind the goal, to a multiple of that of the ten.

When using photoelectric equipment direction deviation as well as the high and low deviation are in trouble, should the measure target projection width is quite dense digits, on the basis of using target projection width to determine the direction of ZhaDian general deviation value and deviation value.

\section{References}

[1] Liwei L, Rongshuang F. Simulated annealing algorithm in solving frequency assignment problem[C]//Advanced Computer Theory and Engineering (ICACTE), 2010 3rd International Conference on. IEEE, 2010, 1: V1-361-V1-364.

[2] Castelino D J, Hurley S, Stephens N M. A tabu search algorithm for frequency assignment[J]. Annals of Operations Research, 1996, 63(2): 301-319.

[3] Alabau M, Idoumghar L, Schott R. New hybrid genetic algorithms for the frequency assignment problem[J]. Broadcasting, IEEE Transactions on, 2002, 48(1): 27-34.

[4] Radiom, S. Aliakbarian, H., etc., A Simple Real-Coded Compact Genetic Algorithm and its Application to Antenna Optimization, Microwave conference, APMC 2007.

[5] Francisco Herrera and Manuel Lozano. Gradual Distributed Real-Coded Genetic Algorithms [J]. IEEE transactions on evolutionary computation, 2000,4(1):43-62.

[6] Díógenes Marcano and Filinto Durán. Synthesis of [7]Antenna Arrays Using Genetic Algorithms [J]. IEEE Antennas and Propagation Magazine, 42(3):12-20.

[7] Wen-Pin Liao, Fu-Lai Chu. Array pattern synthesis with null steering using genetic algorithm by controlling only the current amplitudes[J]. INT. J. ELECTRONICS, 1999, 86(4):445-457.

[8] Wen-Pin Liao, Fu-Lai Chu Application of Genetic Algorithms to Phase-Only Null Steering of Linear Arrays [J] Electromagnetics, 1997, 17:171-183.

[9] Fred Aust in, Michael lew is. Automated Maneuvering Decision for Air-to-Air Combat[R].AIAA-87-2393:659-669 